\title{
Intraoperative mapping during repeat awake craniotomy reveals the functional plasticity of adult cortex
}

\author{
*Derek G. Southwell, MD, PhD, Shawn L. Hervey-Jumper, MD, David W. Perry, PhD, and \\ Mitchel S. Berger, MD \\ Department of Neurological Surgery, University of California, San Francisco, California
}

\begin{abstract}
OBJECTIVE To avoid iatrogenic injury during the removal of intrinsic cerebral neoplasms such as gliomas, direct electrical stimulation (DES) is used to identify cortical and subcortical white matter pathways critical for language, motor, and sensory function. When a patient undergoes more than 1 brain tumor resection as in the case of tumor recurrence, the use of DES provides an unusual opportunity to examine brain plasticity in the setting of neurological disease.
\end{abstract}

METHODS The authors examined 561 consecutive cases in which patients underwent DES mapping during surgery for glioma resection. "Positive" and "negative" sites-discrete cortical regions where electrical stimulation did (positive) or did not (negative) produce transient sensory, motor, or language disturbance-were identified prior to tumor resection and documented by intraoperative photography for categorization into functional maps. In this group of 561 patients, 18 were identified who underwent repeat surgery in which 1 or more stimulation sites overlapped with those tested during the initial surgery. The authors compared intraoperative sensory, motor, or language mapping results between initial and repeat surgeries, and evaluated the clinical outcomes for these patients.

RESULTS A total of 117 sites were tested for sensory ( 7 sites, $6.0 \%$ ), motor ( 9 sites, $7.7 \%$ ), or language (101 sites, $86.3 \%$ ) function during both initial and repeat surgeries. The mean interval between surgical procedures was 4.1 years. During initial surgeries, $95(81.2 \%)$ of 117 sites were found to be negative and $22(18.8 \%)$ of 117 sites were found to be positive. During repeat surgeries, $103(88.0 \%)$ of 117 sites were negative and $14(12.0 \%)$ of 117 were positive. Of the 95 sites that were negative at the initial surgery, $94(98.9 \%)$ were also negative at the repeat surgery, while $1(1.1 \%)$ site was found to be positive. Of the 22 sites that were initially positive, $13(59.1 \%)$ remained positive at repeat surgery, while 9 (40.9\%) had become negative for function. Overall, $6(33.3 \%)$ of 18 patients exhibited loss of function at 1 or more motor or language sites between surgeries. Loss of function at these sites was not associated with neurological impairment at the time of repeat surgery, suggesting that neurological function was preserved through neural circuit reorganization or activation of latent functional pathways.

CONCLUSIONS The adult central nervous system reorganizes motor and language areas in patients with glioma. UItimately, adult neural plasticity may help to preserve motor and language function in the presence of evolving structural lesions. The insight gained from this subset of patients has implications for our understanding of brain plasticity in clinical settings.

http://thejns.org/doi/abs/10.3171/2015.5.JNS142833

KEY WORDS awake craniotomy; brain plasticity; direct electrical stimulation; glioma; surgical technique

$\mathrm{P}$ LASTICITY, or the ability to change in response to experience, is an inherent feature of the brain that allows for the development and maintenance of nervous system function. ${ }^{27}$ Brain plasticity manifests itself through various mechanisms at different levels; representative examples for such mechanisms at the molecular, cellular, and tissue levels, respectively, include trafficking of neurotransmitter receptors, the rearrangement of neuronal axons and dendrites, and the generation of new neurons and glia. ${ }^{5}$ Animal experiments have characterized brain plasticity and described its mechanistic basis in nonhuman subjects, but few detailed and direct investigations of plasticity have been made in humans..$^{12,14,18,27} \mathrm{~A}$ greater knowledge of human brain plasticity, particularly in the setting of disease, is fundamental to understanding the clinical course of neurological conditions, to applying

ABBREVIATIONS ADP = after-discharge potential; DES = direct electrical stimulation; FLAIR = fluid-attenuated inversion-recovery; fMRI = functional MRI; GTR = grosstotal resection; $\mathrm{PET}=$ positron emission tomography; $\mathrm{STR}=$ subtotal resection; TMS = transcranial magnetic stimulation; WHO = World Health Organization. SUBMITTED December 15, 2014. ACCEPTED May 7, 2015.

INCLUDE WHEN CITING Published online November 6, 2015; DOI: 10.3171/2015.5.JNS142833.

* Drs. Southwell and Hervey-Jumper contributed equally to this work. 
current treatment modalities effectively, and to devising novel strategies for the therapeutic modification of neural circuits.

A number of studies have suggested the involvement of brain plasticity in clinical recovery from nervous system pathologies, including ischemic stroke $\mathrm{k}^{23,37,41}$ and infiltrative brain tumors. ${ }^{8,10,13,21,30,38,47}$ These findings, however, were derived from noninvasive and indirect measurements of brain function, such as functional MRI (fMRI), ${ }^{13,37}$ positron emission tomography (PET), ${ }^{38,47}$ and transcranial magnetic stimulation (TMS). ${ }^{19,47}$ Moreover, few of these studies examined brain function in a longitudinal or prospective manner, ${ }^{10,17,21,30,32,37}$ and thus, most were unable to describe how the brain may adapt over time in response to pathology. Here we describe a direct and longitudinal observation of functional brain organization in patients with glioma, the most common intrinsic brain neoplasm.

Gliomas - particularly astrocytomas and oligodendrogliomas-are infiltrative brain tumors that arise from astrocytes, oligodendrocytes, or their precursors. ${ }^{4}$ A basic objective in treatment of a glioma is to safely resect as much tumor as possible..$^{33}$ The goal of complete resection, however, is often countered by the risk of iatrogenic injury, particularly when the tumor lies adjacent to or within functional brain regions. In order to avoid functional deficits following tumor resection, direct electrical stimulation (DES) of neural tissue is used to identify and create a patient-specific map of brain areas that serve sensory, motor, and language functions. By testing the functional eloquence of discrete volumes of brain matter, surgeons are able to identify tissue that can be resected with minimal likelihood of functional deficits. ${ }^{1,9,11,20,25,35}$

In cases that involve postoperative progression of a glioma, patients will sometimes undergo a second surgery in which DES mapping is performed in the same brain region. In these rare instances, repeat DES mapping provides a unique opportunity to directly and longitudinally examine whether brain function reorganizes in the setting of disease. In this study, we examined and compared DES mapping results from patients who underwent 2 or more surgeries for glioma resection. Together, our findings define the stability of DES maps in this population, and provide evidence for the functional reorganization of adult cerebral cortex in the setting of an evolving structural abnormality-specifically, glioma.

\section{Methods}

\section{Patients and Patient Outcome Measurements}

We retrospectively examined 561 consecutive cases involving adult patients (over the age of 18 years) who underwent intraoperative sensory, motor, or language mapping during awake craniotomy for glioma resection. All patients presented with a frontal, parietal, temporal, or insular glioma within or adjacent to areas presumed to serve sensory, motor, or language function. Tumors and adjacent brain areas were initially identified using MRI and, when available, magnetoencephalography and diffusion tensor imaging. All procedures were performed at the University of California, San Francisco, by 1 senior neurosurgeon (M.S.B.) between 1997 and 2014. The institutional review board at the University of California, San Francisco, approved this study.

Twenty-four to 48 hours prior to surgery, a neurophysiologist conducted language and sensorimotor evaluations. Sensory evaluations included testing of light touch, pain, and position sense, while motor evaluations included testing of face, arm, and leg strength (using a 1-5 scale). Depending on tumor location, language evaluation included assessments of object naming (from a 64-item panel), reading, counting, calculation, and visuospatial identification. Intraoperative language testing was performed using only those items that the individual patient had correctly identified during the preoperative evaluation. The senior neurosurgeon also conducted preoperative and intraoperative sensorimotor and language evaluations. Intraoperative language evaluation (described in greater detail below) consisted of tests of naming, reading, calculation, and counting. Only patients with 1) normal preoperative language ( $>90 \%$ preoperative naming accuracy) and sensorimotor examinations and 2) complete perioperative records (intraoperative photographs, hand-drawn intraoperative brain maps, and operative reports) were included in our analysis.

Postoperative sensorimotor and language evaluation was performed by the senior neurosurgeon, neurosurgical resident, and neuro-oncologist. Examinations were completed every day during the postoperative hospitalization and at 1 week, 4-6 weeks, and 3-6 months following surgery. Differences between the examiners' findings were reconciled by accepting the examination result that documented the greater degree of impairment.

\section{Neuroanesthesia}

Propofol (50-100 $\mu \mathrm{g} / \mathrm{kg} /$ minute) or dexmedetomidine $(0.7-2.0 \mu \mathrm{g} / \mathrm{kg} /$ hour $)$, as well as a short-acting opiate such as remifentanil $(0.05-0.1 \mu \mathrm{g} / \mathrm{kg} /$ minute), were used for sedation during the surgical procedure. Sedation was discontinued after the craniotomy and prior to incision of the dura.

\section{Intraoperative Mapping and Tumor Resection}

The intraoperative awake mapping techniques used in this study have been described previously. ${ }^{20,34,35}$ Briefly, the craniotomy was made to expose the tumor and up to $2-3 \mathrm{~cm}$ of surrounding cortical surface. DES of the cerebral cortex was performed using 1-mm bipolar electrodes separated by a distance of $5 \mathrm{~mm}$. To ensure that mapping results were not affected by subclinical seizure activity, electrocorticography was used to measure stimulation-induced after-discharge potentials (ADPs). Stimulation-induced seizures were suppressed by irrigating the exposed brain surface with chilled Ringer's solution. ${ }^{36}$ If seizures were refractory to cold irrigation, intravenous propofol (1 $\mathrm{mg} / \mathrm{kg}$ ) was administered. The initial stimulation intensity was $2.5 \mathrm{~mA}$, and it was then increased up to a maximum of $6 \mathrm{~mA}$, or $1 \mathrm{~mA}$ less than the intensity that evoked ADPs. In all subjects, ADPs were achieved with stimulation intensities that ranged between 2.5 and $6 \mathrm{~mA}$. The typical stimulation current was 3-4 mA. Stimulation sites were spaced over every $1 \mathrm{~cm}^{2}$ of exposed brain surface overly- 
ing the tumor. The stimulation intensity was recorded for each patient's mapping procedure.

When more than 1 functional modality (i.e, sensory, motor, or language) was tested, mapping of sensory and motor sites was performed first, followed by mapping of language sites. A positive sensory site was identified if the patient reported focal paresthesia of the face, trunk, arm, or leg during application of the stimulus. A positive motor site was identified by involuntary movement of the face, arm, or leg, or impaired motor function during active movement by the patient (e.g., finger tapping). Intraoperative language testing was performed by a neurophysiologist in cooperation with the attending neurosurgeon. In accordance with our previously published reports, positive language sites were defined by stimulation-induced anomia, alexia, or speech arrest, in the absence of motor or seizure activity, during 2 out of 3 stimulation trials. ${ }^{35}$ Speech arrest was defined as disruption of number-counting (without mouth or pharyngeal muscle movement), anomia was defined as the inability to name sequential objects presented as line drawings, and alexia was defined as the inability to read words. Stimulation sites were labeled with numbered plastic markers (approximately $5 \mathrm{~mm}$ in width), and the mapping results at each numbered site were transcribed onto a hand-drawn map and dictated in an operative report. The labeled mapping sites were recorded by digital photography prior to and following tumor resection.

Tumor resection was performed using frameless navigational guidance based on the preoperative MRI. Wherever a positive site was identified, tumor resection was performed up to $1 \mathrm{~cm}$ from the center of the stimulation site. Unless necessary to access the tumor, the senior neurosurgeon did not resect tissue that was not involved by the tumor.

\section{Alignment of Maps}

Hand-drawn maps, operative reports, and digital photographs were used to compare mapping results between the initial and repeat surgeries. Digital photographs were oriented and aligned using anatomical landmarks, including the initial resection cavity, gyral and sulcal contours, and surface blood vessels. Stimulation sites were considered overlapping only if the digital photographs demonstrated spatial overlap (between initial and repeat surgeries) in the placement of the 5-mm plastic stimulation site markers. Based on prior studies, this method ensured that the peak current density produced by bipolar stimulation was delivered to discrete and overlapping volumes of tissue (approximately $5 \mathrm{~mm}$ in width). ${ }^{16,24,40}$ Two individuals (D.G.S. and S.H.J.) independently aligned the maps from initial and repeat surgeries and compared the positions of the stimulation sites using intraoperative photographs, handdrawn maps, and operative reports. Sites were considered overlapping only if both individuals had independently scored them as such.

\section{Tumor Volume and Extent of Resection}

Tumors were volumetrically analyzed by measuring hyperintense regions on axial T2-weighted fluid-attenuated inversion-recovery (FLAIR) images (for low-grade gliomas) and T1-weighted contrast-enhanced MR images (for high-grade gliomas). For each case, the tumor was segmented manually across all slices with region-of-interest analysis to compute the volume.

Extent of resection was determined by comparing preoperative MR images with those obtained during the first 48 hours after surgery. Gross-total resection (GTR) was defined as the absence of hyperintense tissue on T2weighted sequences (low-grade gliomas) or the absence of contrast-enhancing tissue on T1-weighted sequences (high-grade gliomas). For the purpose of this study, subtotal resection (STR) was classified as anything other than GTR.

\section{Statistical Analyses}

Descriptive statistics are reported as the mean value ( \pm standard deviation) for continuous variables, unless otherwise specified, and as the frequency of distribution for categorical variables. The Pearson chi-square test was used for categorical analyses, and t-tests were performed for mean comparisons of continuous variables. The Fisher exact test was used if more than $80 \%$ of values were less than 5. All statistics were analyzed using JMP statistical software, version 10.0.2 (SAS Institute, Inc.).

\section{Results}

\section{Characteristics of Patients and Tumors}

Of 561 patients who underwent an initial awake craniotomy with intraoperative mapping, 39 underwent repeat surgery. In 18 of these 39 patients, the repeat surgery involved stimulation of 1 or more sites that had been tested during the initial surgery. In the remaining 21 cases, which were not included in our analysis, there was no overlap of stimulation sites between the initial and repeat surgeries (2 patients), or the mapping records were incomplete (19 patients). Two of the 18 patients underwent a second repeat surgery; thus, a total of 20 repeat surgeries with overlapping sites were analyzed. Our final study population included 12 men (66.7\%) and 6 women (33.3\%; Table 1). Tumors involved the insula (50.0\%), frontal lobe (25.0\%), temporal lobe $(20.0 \%)$, and parietal lobe $(5.0 \%)$. Tumor pathology included World Health Organization (WHO) Grade II (85.0\%) and Grade III (15.0\%) lesions. The mean age of the patients at initial surgery was $34.3 \pm 8.9$ years, and the mean age at repeat surgery was $38.3 \pm 9.8$ years. The mean interval between initial and repeat surgeries was $4.1 \pm 2.1$ years.

\section{DES Mapping}

During the initial surgeries, a total of 583 sites were tested by DES; of these, 117 (20.1\%) were retested during the repeat surgeries and were considered overlapping sites based on alignment of the stimulation maps. Seven (6.0\%) of these 117 sites had been tested for sensory function, 9 for motor function (7.7\%), and 101 for language function (86.3\%). The spatial distribution of overlapping stimulation sites is depicted in Fig. 1. During the initial surgery, $95(81.2 \%)$ of the 117 overlapping sites were found to be negative and $22(18.8 \%)$ were found to be positive. All 95 of the negative sites had been tested for language function. 
TABLE 1. Demographic and clinical characteristics of the study population*

\begin{tabular}{cc}
\hline \multicolumn{1}{c}{ Variable } & Value \\
\hline Sex & $12(66.7 \%)$ \\
\hline Male & $6(33.3 \%)$ \\
\hline Female & $34.3 \pm 8.9$ \\
\hline Age at initial op (yrs, mean \pm SD) & $38.3 \pm 9.8$ \\
\hline Age at repeat op (yrs, mean \pm SD) & $4.1 \pm 2.1$ \\
\hline Interval btwn ops (yrs, mean \pm SD) & \\
\hline Tumor location & $5(25.0 \%)$ \\
\hline Frontal lobe & $4(20.0 \%)$ \\
\hline Temporal lobe & $1(5.0 \%)$ \\
\hline Parietal lobe & $10(50.0 \%)$ \\
\hline Insula & $57.4 \pm 33.6$ \\
\hline Tumor vol (cm ${ }^{3}$, mean \pm SD) & $95 \%$ \\
\hline Extent of tumor resection (1st op) & $17(85.0 \%)$ \\
\hline Tumor histology & $3(15.0 \%)$ \\
\hline WHO Grade II & $0(0.0 \%)$ \\
\hline WHO Grade III
\end{tabular}

* Eighteen patients, 20 repeat stimulation mappings.

Of the remaining 22 sites, 7 (31.8\%) were positive for sensory function during the initial surgeries, 9 (40.9\%) were positive for motor function, and $6(27.3 \%)$ were positive for language function.

During the repeat surgeries, $103(88.0 \%)$ of the 117 overlapping sites were found to be negative and $14(12.0 \%)$ sites were found to be positive. Of the 103 sites found to be negative during the repeat surgeries, $100(97.1 \%)$ had been tested for language function and $3(2.9 \%)$ had been tested for motor function. Of the remaining 14 sites, 7 (50.0\%) were positive for sensory function, 6 (42.9\%) were positive for motor function, and 1 (7.1\%) was positive for language function.

Overall, of the 95 sites found to be negative during the initial surgery, $94(98.9 \%)$ were negative at the time of repeat surgery (negative-negative), while $1(1.1 \%)$ was positive at repeat surgery (negative-positive; Table 2). Negative mapping sites were resected if they were directly involved by tumor, or if their resection was necessary to access the tumor. Some, but not all, negative sites were resected at the time of reoperation. Twenty-two sites were found to be positive during the initial surgery; $13(59.1 \%)$ of these were positive at the time of repeat surgery (positive-positive), while $9(40.9 \%)$ were negative at repeat surgery (positivenegative). Figure 2 depicts stimulation sites tested in a representative patient who exhibited loss of function at a language site. All 7 sensory sites (100\%) exhibited stable function (positive-positive). Six (66.7\%) of 9 motor sites exhibited stable function (positive-positive), while 3 (33.3\%) exhibited loss of function (positive-negative). Six (100\%) of 6 sites that were initially positive for language function later exhibited loss of function (positive-negative), while 1 (1.1\%) of 95 sites initially negative for language function exhibited gain of function (negative-positive). Figure 3 illustrates the distribution of sites that were stable, and sites at which loss or gain of function occurred.

\section{Functional Reorganization and Patient Outcomes}

Seven (38.9\%) of 18 patients demonstrated a change in their functional maps between initial and repeat surgeries;

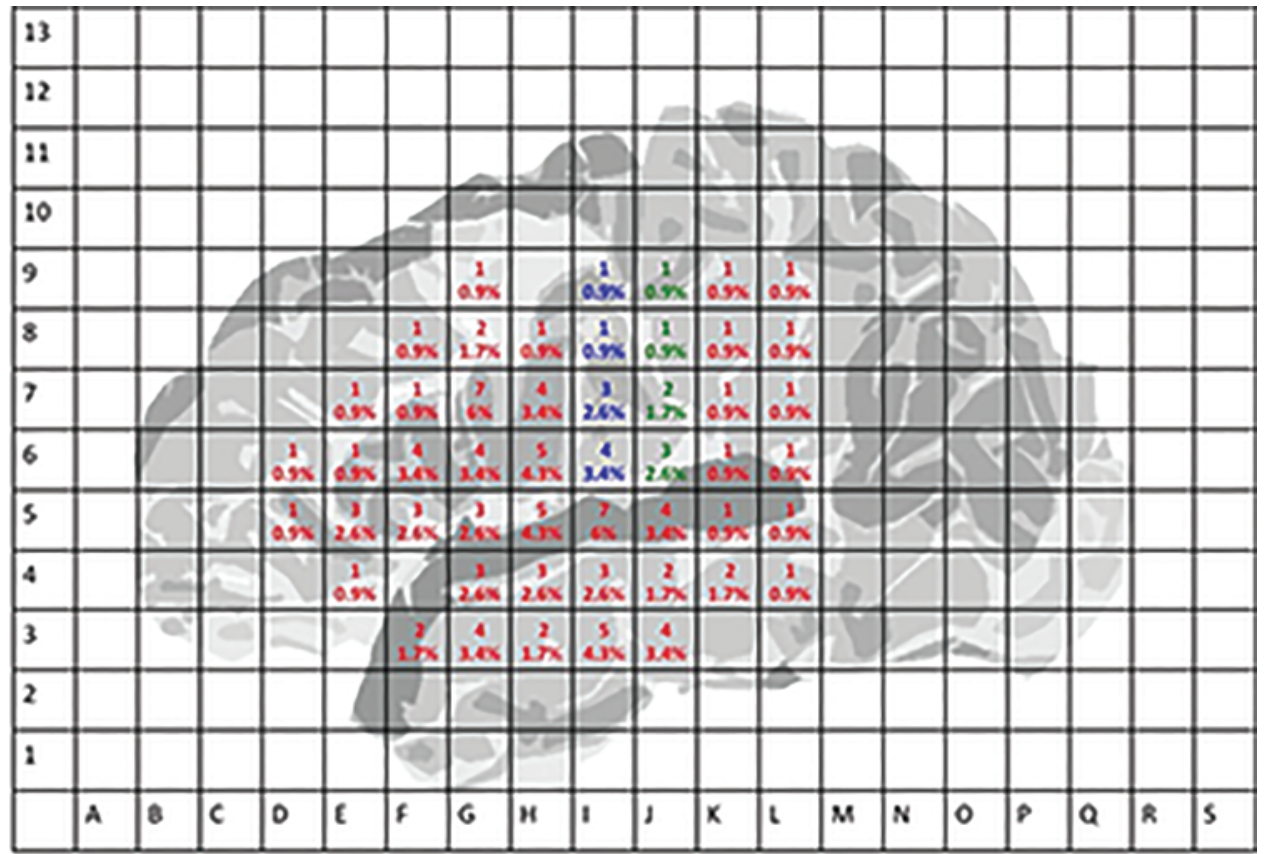

FIG. 1. Mapping of the dominant hemisphere showing the number of overlapping sites tested within each square centimeter of cortex. Percentages indicate the fraction of total sites located within the region of interest. Color indicates the function tested (red $=$ language; blue = motor; green = sensory). A total of 117 cortical sites were tested by DES during both initial and repeat surgeries. Figure is available in color online only. 
TABLE 2. Direct electrical stimulation results from sites tested during both initial and repeat surgeries

\begin{tabular}{|c|c|c|c|c|c|c|}
\hline Function & Neg-Neg Sites & Neg-Pos Sites & Pos-Pos Sites & Pos-Neg Sites & Total Sites Tested & Summary \\
\hline Sensory & 0 & 0 & 7 & 0 & $7(6.0 \%)$ & \\
\hline Motor & 0 & 0 & 6 & 3 & $9(7.7 \%)$ & \\
\hline Language & 94 & 1 & 0 & 6 & $101(86.3 \%)$ & \\
\hline Stable neg function & & & & & & $94 / 95(98.9 \%)$ \\
\hline Gain of function & & & & & & $1 / 95(1.1 \%)$ \\
\hline Stable pos function & & & & & & $13 / 22(59.1 \%)$ \\
\hline Loss of function & & & & & & $9 / 22(40.9 \%)$ \\
\hline
\end{tabular}

6 patients $(33.3 \%)$ lost function at 1 or more sites, while 1 patient $(5.6 \%)$ gained function at 1 site (Table 3$)$. Surprisingly, patients who demonstrated loss of function at 1 or more stimulation sites still exhibited intact or stable motor and speech function, based on clinical examination at the time of repeat surgery; all 4 patients with positive-negative language sites demonstrated $>90 \%$ accuracy on a naming task performed immediately before repeat surgery. Moreover, the 2 patients with positive-negative motor sites (which, in both patients, initially involved facial movements) exhibited no change in motor function between their initial and repeat surgeries. One patient retained intact facial strength, while the other exhibited facial weakness following the initial surgery, which then remained stable at the time of repeat surgery.

Finally, we examined whether demographic, pathological, or treatment-related features differed between those patients who demonstrated a change in their functional maps (Table 3) and those who did not (Table 4). We found no significant difference in age at time of repeat surgery $(38.1 \pm 8.4$ years vs $37.7 \pm 10.8$ years; $\mathrm{p}=0.94)$, WHO grade $(85.7 \%$ low grade vs $84.6 \%$ low grade; $\mathrm{p}=0.99)$, or location $(28.6 \%$ insular vs $61.5 \%$ insular; $p=0.35)$ be- tween those patients who demonstrated a change in their functional maps and those who did not, respectively. Likewise, there was no difference in the extent of resection (42.9\% STR vs $69.2 \%$ STR; $p=0.36)$ or intersurgery interval $(4.7 \pm 2.2$ years vs $3.7 \pm 2.1$ years; $p=0.34)$ between patients who demonstrated a change in their functional maps and those who did not, respectively. Finally, functional reorganization did not appear to be related to history of postoperative adjuvant treatments such as chemotherapy $(14.3 \%$ of patients who demonstrated a change in their maps received chemotherapy vs $61.5 \%$ of the group who demonstrated no change; $\mathrm{p}=0.07)$ or radiation $(0 \%$ vs $0 \%$; $\mathrm{p}=0.99$ ). Tumor volumes at time of the initial surgery, however, were significantly smaller in patients who exhibited functional reorganization $\left(34.1 \pm 23.0 \mathrm{~cm}^{3}\right.$ in those who exhibited reorganization vs $69.9 \pm 32.2 \mathrm{~cm}^{3}$ in those who did not; $\mathrm{p}=0.02$ ).

\section{Discussion}

We examined a rare population of patients who underwent 2 or more awake surgeries in which DES was used to examine brain functional organization. Compared with
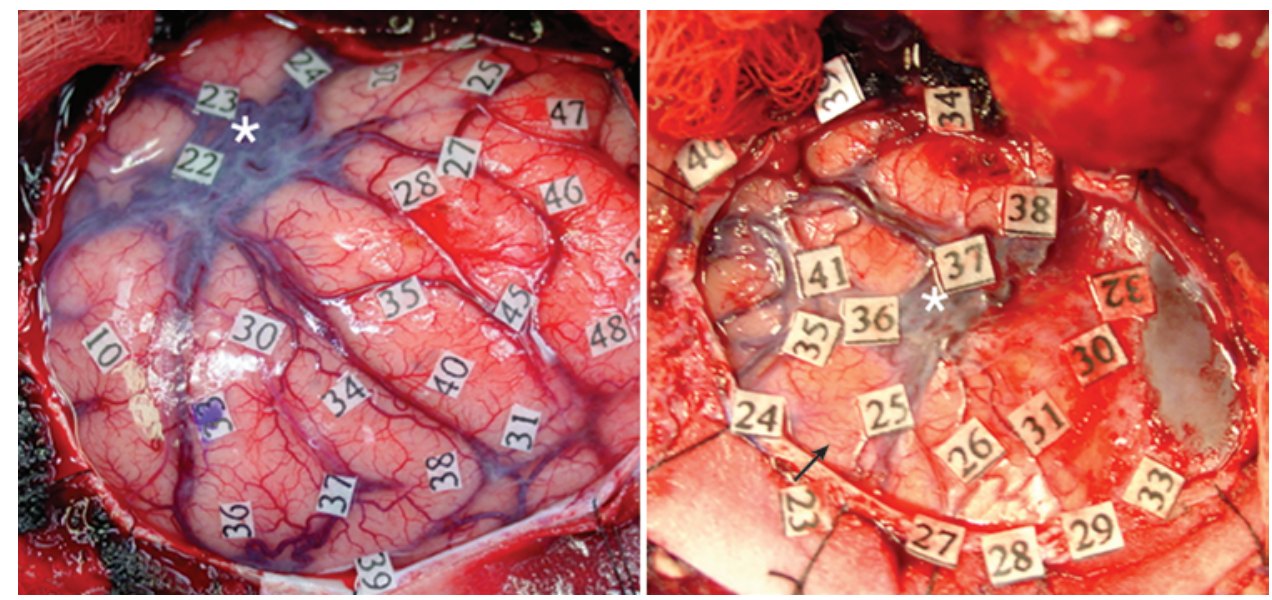

FIG. 2. Sites tested for language function during initial and repeat resections of a WHO Grade II astrocytoma from the left cerebral hemisphere of a male patient. Left: The patient was 24.2 years of age at the time of the initial surgery. Stimulation of Site 10 caused speech arrest; the other sites did not exhibit function. Right: The patient was 26.8 years of age at the time of repeat surgery. No sites exhibited function, including Site 23, which was considered overlapping with Site 10 from the initial surgery (right panel); site markers were placed on the adjacent dura for stimulation sites just inside the dural edge (black arrow). Despite loss of function at this site, the patient exhibited intact speech at the time of the repeat surgery. For both panels, the top of the image is inferior and the right is anterior. For purposes of orientation, Sites 23 (left) and 37 (right) are placed on the same point, and are labeled with an asterisk. Figure is available in color online only. 

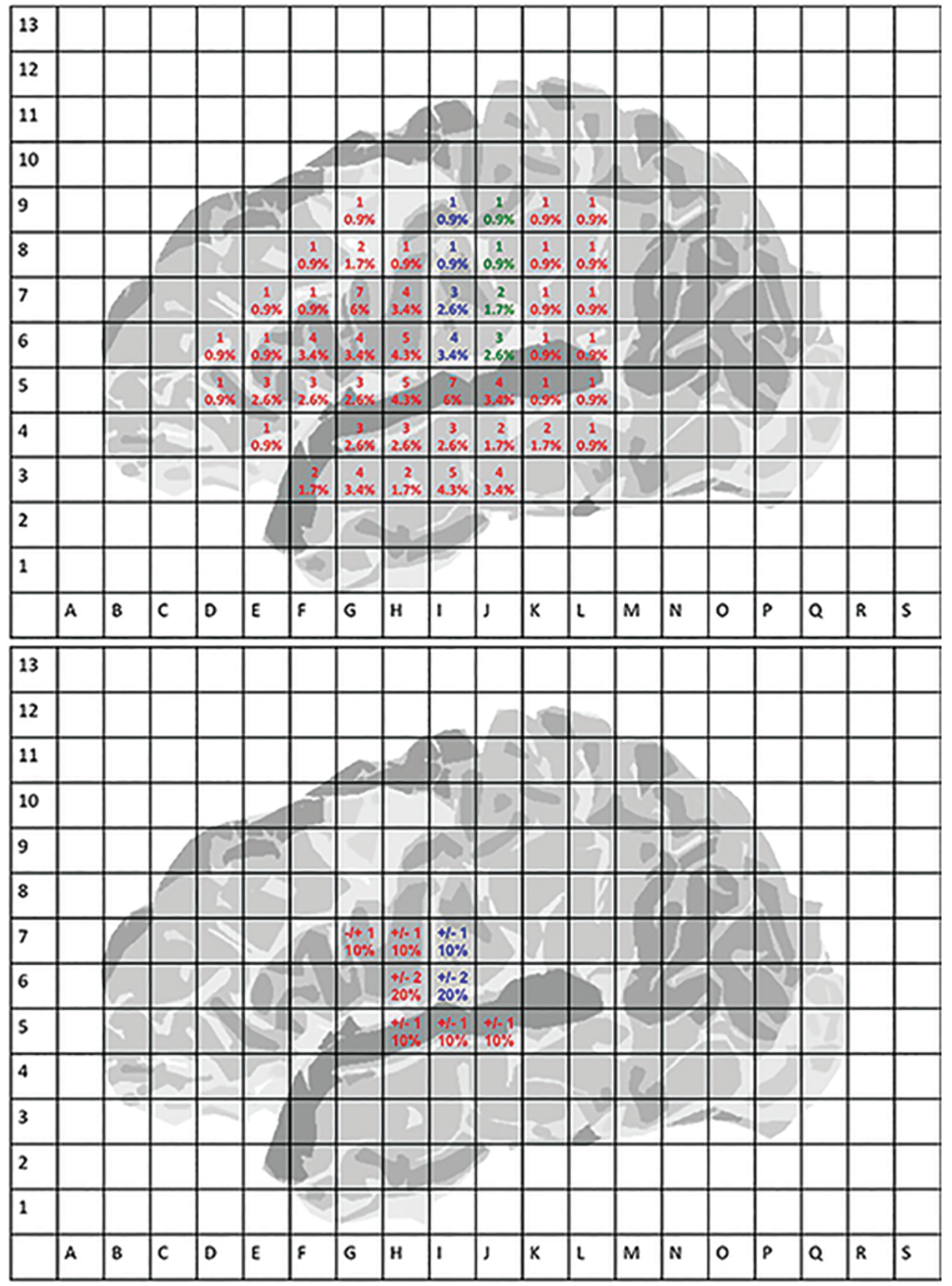

FIG. 3. Results of repeat stimulation mappings of the dominant hemisphere, indicating the number of overlapping sites tested within each square centimeter of cortex. A total of 117 cortical sites were tested by DES during both an initial and repeat surgery. Of these, 107 (91.5\%) exhibited stable (negative-negative or positive-positive) function (upper). Ten sites (8.5\%) exhibited change of function (positive-negative [+/-] or negative-positive [-/+]; lower). Percentages indicate the fraction of stable or unstable sites located within the region of interest. Color indicates the function tested (red = language; blue = motor; green = sensory). Figure is available in color online only.

noninvasive techniques such as fMRI, PET, and TMS, DES is considered the most accurate method for identifying functional neural tissue in humans. ${ }^{3,15,29,31,42,43,45}$ By examining the function of discrete cortical areas across intervals that ranged from months to years, we provide evidence for the reorganization of motor and language circuits in adult glioma patients. Altogether, this study represents the first large, longitudinal study of the stability and reorganization of DES maps. Our findings expand upon limited case reports hinting that adult plasticity may preserve sensorimotor and language function in the face of infiltrative brain tumors. ${ }^{10,17,21,30,32}$

We identified several positive-negative cortical sites, which, by means of bipolar electrode stimulation, demonstrated functional significance during an initial surgery, but not during a repeat surgery (Fig. 3, lower panel). During 
TABLE 3. Characteristics of patients who demonstrated a change in functional maps between initial and repeat surgeries

\begin{tabular}{|c|c|c|c|c|c|c|c|c|c|}
\hline Case No. & Sex & $\begin{array}{l}\text { Tumor } \\
\text { Loc }\end{array}$ & $\begin{array}{l}\text { Pathology \& } \\
\text { WHO Grade }\end{array}$ & $\begin{array}{l}\text { Age } \\
\text { (yrs) }\end{array}$ & $\begin{array}{c}\text { Interval } \\
\text { Btwn Ops } \\
\text { (mos) }\end{array}$ & $\begin{array}{l}\text { Stim } \\
\text { Intensity } \\
(\mathrm{mA})\end{array}$ & Stim Result(s) & $\begin{array}{l}\text { Naming Accuracy } \\
\text { at Repeat Op }\end{array}$ & $\begin{array}{l}\text { Motor Function at } \\
\text { Repeat Op }\end{array}$ \\
\hline 1 & Female & Temporal & $\begin{array}{l}\text { OA II } \\
\text { AA III }\end{array}$ & $\begin{array}{l}26.7 \\
32.8\end{array}$ & 73.9 & $\begin{array}{l}4 \\
3\end{array}$ & Pos-neg language & $100 \%$ & Intact \\
\hline 2 & Male & Temporal & $\begin{array}{l}\text { AA III } \\
\text { AA III }\end{array}$ & $\begin{array}{l}44.5 \\
47.2\end{array}$ & 28.6 & $\begin{array}{l}5 \\
6\end{array}$ & Neg-pos language & $100 \%$ & Intact \\
\hline 3 & Male & Frontal & $\begin{array}{l}\text { A II } \\
\text { AA III }\end{array}$ & $\begin{array}{l}43.9 \\
49.3\end{array}$ & 66.3 & $\begin{array}{l}2.5 \\
5\end{array}$ & Pos-neg motor & $100 \%$ & Stable facial weakness \\
\hline 4 & Male & Frontal & $\begin{array}{l}\text { OD II } \\
\text { OD II }\end{array}$ & $\begin{array}{l}26.8 \\
34.0\end{array}$ & 87.7 & $\begin{array}{l}4 \\
4 \\
\end{array}$ & 2 pos-neg language & $100 \%$ & Intact \\
\hline 5 & Male & Insular & $\begin{array}{l}A \| I \\
A \|\end{array}$ & $\begin{array}{l}24.2 \\
26.8\end{array}$ & 32.4 & $\begin{array}{l}4 \\
6\end{array}$ & Pos-neg language & $100 \%$ & Intact \\
\hline 6 & Female & Frontal & $\begin{array}{l}\text { OA II } \\
\text { OA II }\end{array}$ & $\begin{array}{l}31.6 \\
33.6\end{array}$ & 24.6 & $\begin{array}{l}\text { NR } \\
4.5\end{array}$ & 2 pos-neg motor & $100 \%$ & Intact \\
\hline 7 & Male & Insular & $\begin{array}{l}\text { A II } \\
\text { OD \| }\end{array}$ & $\begin{array}{l}36.2 \\
43.1\end{array}$ & 83.8 & $\begin{array}{l}6 \\
5\end{array}$ & 2 pos-neg language & $100 \%$ & Intact \\
\hline
\end{tabular}

the initial surgeries, stimulation of positive-negative motor and language sites elicited involuntary motor responses or transient loss of speech, respectively, indicating their functional requirement for movement or language. These sites were preserved during the initial surgery and subsequently tested during the repeat surgery, at which time stimulation had no effect on movement or speech, indicating they were no longer functional. Our language and sensorimotor mapping technique remained unchanged between all initial and repeat surgeries. Surprisingly, loss of function

TABLE 4. Characteristics of patients who did not demonstrate a change in functional maps between initial and repeat surgeries

\begin{tabular}{|c|c|c|c|c|c|c|c|c|c|}
\hline $\begin{array}{l}\text { Case } \\
\text { No. }\end{array}$ & Sex & Tumor Loc & $\begin{array}{l}\text { Pathology \& } \\
\text { WHO Grade }\end{array}$ & $\begin{array}{l}\text { Age } \\
\text { (yrs) }\end{array}$ & $\begin{array}{c}\text { Interval } \\
\text { Btwn Ops } \\
\text { (mos) }\end{array}$ & $\begin{array}{c}\text { Stim } \\
\text { Intensity } \\
(\mathrm{mA})\end{array}$ & Stim Result(s) & $\begin{array}{l}\text { Naming } \\
\text { Accuracy at } \\
\text { Repeat Op }\end{array}$ & $\begin{array}{c}\text { Motor } \\
\text { Function } \\
\text { at Repeat } \\
\text { Op }\end{array}$ \\
\hline 1 & Male & Insular & $\begin{array}{l}\text { OA II } \\
\text { AA III }\end{array}$ & $\begin{array}{l}29 \\
32\end{array}$ & 94.1 & $\begin{array}{l}5.5 \\
5\end{array}$ & Neg-neg language & $100 \%$ & Intact \\
\hline 2 & Male & Insular & $\begin{array}{l}\text { AA III } \\
\text { AA III }\end{array}$ & $\begin{array}{l}30 \\
35\end{array}$ & 60.6 & $\begin{array}{l}5 \\
5\end{array}$ & Neg-neg language & $100 \%$ & Intact \\
\hline 3 & Female & Insular & $\begin{array}{l}A \| \\
A A \| I I\end{array}$ & $\begin{array}{l}32 \\
40\end{array}$ & 71.5 & $\begin{array}{l}6 \\
4\end{array}$ & Neg-neg language & $100 \%$ & Intact \\
\hline 4 & Male & Insular & $\begin{array}{l}\text { OD II } \\
\text { OD II }\end{array}$ & $\begin{array}{l}51 \\
58\end{array}$ & 80 & $\begin{array}{l}6 \\
4\end{array}$ & Neg-neg language & $100 \%$ & Intact \\
\hline 5 & Male & Temporal & $\begin{array}{l}\text { OD II } \\
\text { OD II }\end{array}$ & $\begin{array}{l}52 \\
57\end{array}$ & 70.6 & $\begin{array}{l}6 \\
6\end{array}$ & Neg-neg language & $100 \%$ & Intact \\
\hline 6 & Female & Frontal & $\begin{array}{l}\text { AA III } \\
\text { AA III }\end{array}$ & $\begin{array}{l}24 \\
26\end{array}$ & 28.2 & $\begin{array}{l}4.5 \\
4.5\end{array}$ & $\begin{array}{l}\text { Pos-pos motor, neg } \\
\text { neg language }\end{array}$ & $100 \%$ & Intact \\
\hline 7 & Female & Insular & $\begin{array}{l}A \| \\
A A \| I I\end{array}$ & $\begin{array}{l}32 \\
33\end{array}$ & 17 & $\begin{array}{l}5.5 \\
4\end{array}$ & Pos-pos motor & $100 \%$ & Intact \\
\hline 8 & Male & Frontal & $\begin{array}{l}\text { OA II } \\
\text { AA III }\end{array}$ & $\begin{array}{l}20 \\
21\end{array}$ & 13.6 & $\begin{array}{l}5 \\
4\end{array}$ & Pos-pos sensory & $100 \%$ & Intact \\
\hline 9 & Female & Insular & $\begin{array}{l}\text { OD II } \\
\text { OD II }\end{array}$ & $\begin{array}{l}43 \\
47\end{array}$ & 48.4 & $\begin{array}{l}5 \\
5\end{array}$ & Neg-neg language & $100 \%$ & Intact \\
\hline 10 & Male & Insular & $\begin{array}{l}A \| \\
A A \| I\end{array}$ & $\begin{array}{l}38 \\
43\end{array}$ & 61.4 & $\begin{array}{l}4 \\
3\end{array}$ & Neg-neg language & $100 \%$ & Intact \\
\hline 11 & Male & Parietal & $\begin{array}{l}\text { A II } \\
\text { GBM }\end{array}$ & $\begin{array}{l}24 \\
28\end{array}$ & 55.6 & $\begin{array}{l}4.5 \\
4.5\end{array}$ & $\begin{array}{l}\text { Neg-neg language, } \\
\text { pos-pos sensory }\end{array}$ & $100 \%$ & Intact \\
\hline
\end{tabular}

$\mathrm{GBM}=$ glioblastoma 
at these sites - which were once required for normal motor function or speech-was not associated with new clinical deficits, based on patient examination prior to the repeat surgery. The probable explanation for this phenomenon is that between surgeries, mechanisms of brain plasticity had facilitated the remodeling of neural circuitry or the activation of latent functional pathways, such that these sites were no longer required for motor or speech output. ${ }^{5-7}$

The traditional concept of central nervous system organization has separated the brain into "silent" and "eloquent" areas. Conditions that violate eloquent areas are thought to have functional consequences, while those involving silent regions do not cause neurological deficit. A number of studies involving functional imaging examined the neurological basis for language and motor recovery in glioma patients. Noninvasive methods such as fMRI, magnetoencephalography, diffusion tensor imaging, and PET allow for the localization of function in relation to structural brain lesions and demonstrate relocalization of eloquent areas in some patients. ${ }^{44,45}$ For example, fMRI evaluation of patients with low-grade supplementary motor area gliomas has suggested development of eloquence in premotor and supplementary motor areas. ${ }^{6}$ It is currently unknown if factors intrinsic to gliomas may directly promote functional reorganization, and whether reorganization is an intrinsic capacity of the brain.

Of the several factors we examined, tumor volume was the only one that differed between patients who demonstrated loss or gain of function and those who did not. Smaller tumor volumes appeared to be associated with a change in function, which, in the majority of cases, was a loss of function. This may reflect the possibility that, in patients with larger tumors, functional sites had already been reorganized to sites remote from the peritumoral areas mapped during the initial surgery.

Previous case reports have described single examples of loss of function at motor ${ }^{17,30}$ and language ${ }^{21,32}$ sites in glioma patients. In only 1 instance was gain of function observed, and that was at a site positive for language function during a repeat surgery but not during the initial surgery. ${ }^{21}$ In the current study, we describe 7 patients who demonstrated changes in their functional maps. Similar to prior reports, we observed a higher incidence of loss of function (at $40.9 \%$ of sites that were initially positive) than gain of function (at $1.1 \%$ of sites that were initially negative). As previously described, our surgical technique utilizes a limited exposure of the cortical surface, through which only a small margin of normal, peritumoral brain tissue is exposed and tested by stimulation mapping. ${ }^{35}$ Thus, we were more likely to identify negative sites - which are expected to be close to, or involved by the tumor-and less likely to identify sites that were positive during the second surgery. This bias makes it difficult to identify negative-positive sites where "compensatory" gain of function may have occurred between surgeries. Indeed, PET, fMRI, and TMS studies ${ }^{44,45}$ have suggested that negative-positive sites can occur as far away as the contralateral cerebral hemisphere, well outside areas we tested by DES mapping.

Broca and Wernicke established classic theories of brain organization by examining language function in patients with focal brain lesions.,46 Later, through the use of electrical stimulation during epilepsy and brain tumor surgeries, Penfield and colleagues validated and extended these theories, ${ }^{28}$ while developing mapping techniques still used today for surgeries of the dominant cerebral hemisphere. In recent decades, however, intraoperative mapping studies have identified greater patient-to-patient variability in functional localization than has been classically described..$^{25,26,35}$ A possible explanation for this variability, as suggested by this study and others, ${ }^{7,10,21,30}$ is that brain plasticity, in the face of pathologies that vary between patients, produces unique and patient-specific patterns of brain organization. Brain tumor patients, especially those with slower-growing lesions, may have already undergone functional reorganization prior to surgical treatment, ${ }^{8}$ and thus, their sensorimotor and language maps may not reflect the native, canonical organization of the nondiseased brain, if such an organization does exist.

The safety and effectiveness of brain tumor surgery will ultimately benefit from a better understanding of how brain function is localized and reorganized. It has been suggested that the extent of glioma resection can be maximized through sequential procedures, between which functional reorganization is allowed to occur. ${ }^{10,30}$ With advances in noninvasive methods for identifying sensorimotor and language circuits, such as fMRI, TMS, and magnetoencephalography, reorganization could perhaps be carefully observed, with the aim of performing a more aggressive resection once functional neural circuits have developed in areas remote from the lesion. By manipulating brain plasticity through pharmacological, cellular, or electrical stimulation-based strategies, ${ }^{5,22,39}$ surgeons could perhaps enhance brain reorganization to allow for a greater extent of resection, and to facilitate the maintenance or recovery of sensorimotor and speech function in other disease states.

Finally, with respect to tumor surgery in eloquent brain areas, functional reorganization necessitates patient-specific resection guided by DES mapping. In cases of reoperation, surgeons should not rely on mapping results obtained during the initial surgery, because doing so may lead to the resection of tissue that has since gained function, or may result in incomplete resection due to the avoidance of tissue that was previously functional.

\section{Conclusions}

Our results suggest that the adult central nervous system reorganizes motor and language areas in patients with glioma. These findings have implications for our understanding of brain plasticity in clinical settings, and they highlight the necessity of intra-operative mapping to guide patient-specific tumor resection.

\section{References}

1. Berger MS, Ojemann GA: Intraoperative brain mapping techniques in neuro-oncology. Stereotact Funct Neurosurg 58:153-161, 1992

2. Berker EA, Berker AH, Smith A: Translation of Broca's 1865 report. Localization of speech in the third left frontal convolution. Arch Neurol 43:1065-1072, 1986

3. Binder JR, Frost JA, Hammeke TA, Cox RW, Rao SM, Prieto T: Human brain language areas identified by functional magnetic resonance imaging. J Neurosci 17:353-362, 1997 
4. DeAngelis LM: Brain tumors. N Engl J Med 344:114-123, 2001

5. Duffau H: Brain plasticity: from pathophysiological mechanisms to therapeutic applications. J Clin Neurosci 13:885897, 2006

6. Duffau H: Lessons from brain mapping in surgery for lowgrade glioma: insights into associations between tumour and brain plasticity. Lancet Neurol 4:476-486, 2005

7. Duffau H: New concepts in surgery of WHO grade II gliomas: functional brain mapping, connectionism and plasticity-a review. J Neurooncol 79:77-115, 2006

8. Duffau H, Capelle L, Denvil D, Sichez N, Gatignol P, Lopes $\mathrm{M}$, et al: Functional recovery after surgical resection of low grade gliomas in eloquent brain: hypothesis of brain compensation. J Neurol Neurosurg Psychiatry 74:901-907, 2003

9. Duffau H, Capelle L, Sichez J, Faillot T, Abdennour L, Law Koune JD, et al: Intra-operative direct electrical stimulations of the central nervous system: the Salpêtrière experience with 60 patients. Acta Neurochir (Wien) 141:1157-1167, 1999

10. Duffau H, Denvil D, Capelle L: Long term reshaping of language, sensory, and motor maps after glioma resection: a new parameter to integrate in the surgical strategy. J Neurol Neurosurg Psychiatry 72:511-516, 2002

11. Engel AK, Moll CK, Fried I, Ojemann GA: Invasive recordings from the human brain: clinical insights and beyond. Nat Rev Neurosci 6:35-47, 2005

12. Espinosa JS, Stryker MP: Development and plasticity of the primary visual cortex. Neuron 75:230-249, 2012

13. Fandino J, Kollias SS, Wieser HG, Valavanis A, Yonekawa Y: Intraoperative validation of functional magnetic resonance imaging and cortical reorganization patterns in patients with brain tumors involving the primary motor cortex. J Neurosurg 91:238-250, 1999

14. Feldman DE, Brecht M: Map plasticity in somatosensory cortex. Science 310:810-815, 2005

15. Giussani C, Roux FE, Ojemann J, Sganzerla EP, Pirillo D, Papagno C: Is preoperative functional magnetic resonance imaging reliable for language areas mapping in brain tumor surgery? Review of language functional magnetic resonance imaging and direct cortical stimulation correlation studies. Neurosurgery 66:113-120, 2010

16. Haglund MM, Ojemann GA, Blasdel GG: Optical imaging of bipolar cortical stimulation. J Neurosurg 78:785-793, 1993

17. Hayashi Y, Nakada M, Kinoshita M, Hamada J: Functional reorganization in the patient with progressing glioma of the pure primary motor cortex: a case report with special reference to the topographic central sulcus defined by somatosensory-evoked potential. World Neurosurg 82:536.e1-536.e4, 2014

18. Hensch TK: Critical period regulation. Annu Rev Neurosci 27:549-579, 2004

19. Kawashima A, Krieg SM, Faust K, Schneider H, Vajkoczy P, Picht T: Plastic reshaping of cortical language areas evaluated by navigated transcranial magnetic stimulation in a surgical case of glioblastoma multiforme. Clin Neurol Neurosurg 115:2226-2229, 2013

20. Keles GE, Lundin DA, Lamborn KR, Chang EF, Ojemann G, Berger MS: Intraoperative subcortical stimulation mapping for hemispherical perirolandic gliomas located within or adjacent to the descending motor pathways: evaluation of morbidity and assessment of functional outcome in 294 patients. J Neurosurg 100:369-375, 2004

21. Krieg SM, Sollmann N, Hauck T, Ille S, Meyer B, Ringel F: Repeated mapping of cortical language sites by preoperative navigated transcranial magnetic stimulation compared to repeated intraoperative DCS mapping in awake craniotomy. BMC Neurosci 15:20, 2014

22. Maya Vetencourt JF, Sale A, Viegi A, Baroncelli L, De Pasquale R, O'Leary OF, et al: The antidepressant fluox- etine restores plasticity in the adult visual cortex. Science 320:385-388, 2008

23. Murphy TH, Corbett D: Plasticity during stroke recovery: from synapse to behaviour. Nat Rev Neurosci 10:861-872, 2009

24. Nathan SS, Sinha SR, Gordon B, Lesser RP, Thakor NV: Determination of current density distributions generated by electrical stimulation of the human cerebral cortex. Electroencephalogr Clin Neurophysiol 86:183-192, 1993

25. Ojemann G, Ojemann J, Lettich E, Berger M: Cortical language localization in left, dominant hemisphere. An electrical stimulation mapping investigation in 117 patients. J Neurosurg 71:316-326, 1989

26. Ojemann GA: Cortical organization of language. J Neurosci 11:2281-2287, 1991

27. Pascual-Leone A, Amedi A, Fregni F, Merabet LB: The plastic human brain cortex. Annu Rev Neurosci 28:377-401, 2005

28. Penfield W: Some observations on the cerebral cortex of man. Proc R Soc Lond B Biol Sci 134:329-347, 1947

29. Picht T, Krieg SM, Sollmann N, Rösler J, Niraula B, Neuvonen T, et al: A comparison of language mapping by preoperative navigated transcranial magnetic stimulation and direct cortical stimulation during awake surgery. Neurosurgery 72:808-819, 2013

30. Robles SG, Gatignol P, Lehéricy S, Duffau H: Long-term brain plasticity allowing a multistage surgical approach to World Health Organization Grade II gliomas in eloquent areas. J Neurosurg 109:615-624, 2008

31. Roux FE, Boulanouar K, Lotterie JA, Mejdoubi M, LeSage JP, Berry I: Language functional magnetic resonance imaging in preoperative assessment of language areas: correlation with direct cortical stimulation. Neurosurgery 52:13351347,2003

32. Saito T, Muragaki Y, Miura I, Tamura M, Maruyama T, Nitta M, et al: Functional plasticity of language confirmed with intraoperative electrical stimulations and updated neuronavigation: case report of low-grade glioma of the left inferior frontal gyrus. Neurol Med Chir (Tokyo) 54:587-592, 2014

33. Sanai N, Berger MS: Extent of resection influences outcomes for patients with gliomas. Rev Neurol (Paris) 167:648-654, 2011

34. Sanai N, Berger MS: Intraoperative stimulation techniques for functional pathway preservation and glioma resection. Neurosurg Focus 28(2):E1, 2010

35. Sanai N, Mirzadeh Z, Berger MS: Functional outcome after language mapping for glioma resection. $\mathbf{N}$ Engl J Med 358:18-27, 2008

36. Sartorius CJ, Berger MS: Rapid termination of intraoperative stimulation-evoked seizures with application of cold Ringer's lactate to the cortex. Technical note. J Neurosurg 88:349351,1998

37. Saur D, Lange R, Baumgaertner A, Schraknepper V, Willmes $\mathrm{K}$, Rijntjes M, et al: Dynamics of language reorganization after stroke. Brain 129:1371-1384, 2006

38. Seitz RJ, Huang Y, Knorr U, Tellmann L, Herzog H, Freund HJ: Large-scale plasticity of the human motor cortex. Neuroreport 6:742-744, 1995

39. Southwell DG, Froemke RC, Alvarez-Buylla A, Stryker MP, Gandhi SP: Cortical plasticity induced by inhibitory neuron transplantation. Science 327:1145-1148, 2010

40. Szelényi A, Bello L, Duffau H, Fava E, Feigl GC, Galanda $\mathrm{M}$, et al: Intraoperative electrical stimulation in awake craniotomy: methodological aspects of current practice. Neurosurg Focus 28(2):E7, 2010

41. Talelli P, Greenwood RJ, Rothwell JC: Arm function after stroke: neurophysiological correlates and recovery mechanisms assessed by transcranial magnetic stimulation. Clin Neurophysiol 117:1641-1659, 2006

42. Tarapore PE, Findlay AM, Honma SM, Mizuiri D, Houde JF, 
Berger MS, et al: Language mapping with navigated repetitive TMS: proof of technique and validation. Neuroimage 82:260-272, 2013

43. Tarapore PE, Tate MC, Findlay AM, Honma SM, Mizuiri D, Berger MS, et al: Preoperative multimodal motor mapping: a comparison of magnetoencephalography imaging, navigated transcranial magnetic stimulation, and direct cortical stimulation. J Neurosurg 117:354-362, 2012

44. Thiel A, Habedank B, Winhuisen L, Herholz K, Kessler J, Haupt WF, et al: Essential language function of the right hemisphere in brain tumor patients. Ann Neurol 57:128-131, 2005

45. Thiel A, Herholz K, Koyuncu A, Ghaemi M, Kracht LW, Habedank B, et al: Plasticity of language networks in patients with brain tumors: a positron emission tomography activation study. Ann Neurol 50:620-629, 2001

46. Wernicke C: The aphasic symptom-complex: a psychological study on an anatomical basis. Arch Neurol 22:280-282, 1970

47. Wunderlich G, Knorr U, Herzog H, Kiwit JC, Freund HJ, Seitz RJ: Precentral glioma location determines the displacement of cortical hand representation. Neurosurgery 42:1827,1998

\section{Disclosure}

The authors report no conflicts of interest pertaining to the materials or methods used in this study or the findings specified in this paper.

\section{Author Contributions}

Conception and design: Berger, Southwell, Hervey-Jumper. Acquisition of data: all authors. Analysis and interpretation of data: all authors. Drafting the article: Berger, Southwell, HerveyJumper. Critically revising the article: Berger, Southwell, HerveyJumper. Reviewed submitted version of manuscript: all authors. Approved the final version of the manuscript on behalf of all authors: Berger. Study supervision: Berger.

\section{Correspondence}

Mitchel S. Berger, Department of Neurological Surgery, University of California, San Francisco, 505 Parnassus Ave., Rm. M779, San Francisco, CA 94143-0112. email: bergerm@ neurosurg.ucsf.edu. 